\title{
Genetic Diversity Analysis of Rice Landraces of NW Himalayas Using RAPD and ISSR Markers
}

\author{
Ritu Sood, Sanchit Thakur, Neelam Bhardwaj" and R.P. Kaushik \\ College of Agriculture, CSK Himachal Pradesh Agricultural University, \\ Palampur-176062, India \\ *Corresponding author
}

\section{A B S T R A C T}

Forty seven landraces of rice collected from different agro-climatic zones of Himachal Pradesh along with three check varieties were used in the present investigation for the

\section{Keywords}

RAPD, ISSR, Genetic diversity, Rice landraces

Article Info

Accepted:

07 March 2018

Available Online:

10 April 2018 diversity studies using molecular markers to know the their genetic relationship. Higher level of polymorphism was detected by both RAPD and ISSR analysis but the ISSR polymorphism percentage was higher than that of RAPD. Using fifteen RAPD and eleven ISSR primers, 81.2 and 86.4 percent of DNA polymorphism could be detected among these genotypes. The average Jaccard's similarity coefficient based on RAPD, ISSR and combined RAPD and ISSR analysis was $0.49,0.62$ and 0.57 , respectively. Combined analysis of RAPD and ISSR showed that out of 50 landraces, 44 are grouped in Cluster I. Grouping of majority of the genotypes into one cluster suggested affinity among the genotypes indicating their origin in same geographical area. RAPD showed the landraces 'IC 3131155' and 'Sukara' as most divergent ones, while the land races 'Local Variety' and 'Lalzhini' are most diverse as per the ISSR result. The present study revealed the existence of sufficient amount of genetic variability among the landraces, which could be exploited further in the breeding programme.

\section{Introduction}

Rice is highly polymorphic species with wide geographical and eco-genetic differentiation. Many farmers in India still grow local land races under different names and they also bring some varieties from distant places and start cultivating them with local name (Singh et al., 2006). The indigenous rice germplasm of Northwest Himalayas, including Himachal Pradesh is enriched with wide genetic diversity and valuable gene system for yield attributes and adaptability. In Himachal
Pradesh red pericarped and purple leaved rice landraces during long course of evolution has been individualized and conserved by the farmers which contain 2-3 times higher iron and zinc content than that of white rice varieties fetching premium prices in the market. These are also used by the local farmers to fight the wild rice problems. These landraces are neither exhaustive nor sufficient to represent fully the genetic diversity of the region and also facing threat from high yielding varieties (HYVs). Hence, their identification, conservation and classification 
need documentation for utilization in breeding (Bhuyan et al., 2007). DNA markers are known to be powerful and reliable tools for discerning variation within the plant germplasm. Among developed genetic markers, Random Amplified Polymorphic DNA (RAPD) and Inter Simple Sequence Repeats (ISSR) have been widely used for diversity analysis by several groups (Virk et al., 2000; Qian et al., 2001; Bhuyan et al., 2007; Mathure et al., 2010). The present study RAPD and ISSR markers are used to evaluate the pattern of genetic variability and relatedness among landraces of Himachal Pradesh. The data generated from the study will be useful for of maintenance and differentiation of various landraces which are preserved. It would also be helpful to the plant breeders to select readily the diverse parents which will add new germplasm base for future rice breeding progammes.

\section{Materials and Methods}

In the present study, the material comprised 47 land races of rice collected from different parts of Chamba, Kangra, Kullu, Shimla and Mandi districts of Himachal Pradesh and maintained at Rice and Wheat Research Centre, Malan of CSK Himachal Pradesh Agriculture University, Palampur, India. Besides, there were three checks, RP-2421, HPR-2143 and China-988 (Table 1). Seeds of 50 landraces of rice were grown in glass house under controlled conditions. After 30 days of growth leaves were plucked and frozen in liquid nitrogen for DNA extraction. Genomic DNA of e 50 landraces were isolated following the CTAB method of (Murray and Thompson, 1980). About $1 \mathrm{~g}$ fresh juvenile leaves were collected from each genotype, cut into small pieces with sterilized scissor and ground to fine powder in liquid nitrogen ($196^{\circ} \mathrm{C}$ ) in a oven baked pestle and mortar. The quality of DNA was determined by electrophoresis on agarose gel. PCR amplification was performed in $20 \mu$ volume consisting of $1.6 \mu \mathrm{l}$ of dNTP mix $(0.2 \mathrm{mM}$ each of dATP, dGTP, dCTP and dTTP), 0.16 $\mu l$ TaqDNA polymerase, $2 \mu$ DNA template, $1.6 \mu \mathrm{l}$ of $100 \mu \mathrm{M}$ primer, $2 \mu \mathrm{l}$ of $10 \mathrm{x}$ PCR buffer, $1.2 \mu \mathrm{l}$ of $\mathrm{MgCl}_{2}(25 \mathrm{mM})$ and $11.44 \mu \mathrm{l}$ of sterilized distilled water. Reaction mixture was vortexed and centrifuged briefly. Amplification was carried out in a thermal cycler, programmed for $5 \mathrm{~min}$ at $94^{\circ} \mathrm{C}$ for initial denaturation and 39 cycles consisting of $1 \mathrm{~min}$ at $94^{\circ} \mathrm{C}, 1 \mathrm{~min}$ at $37^{\circ} \mathrm{C}$ and $2 \mathrm{~min}$ at $72^{\circ} \mathrm{C}$ with final 7 min extension at $72^{\circ} \mathrm{C}$ using the fastest ramp times between the temperature transitions.

For ISSR assay, 10pmol of each primer was used keeping other ingredients the same as that of RAPD. For this, the initial denaturation was at $95^{\circ} \mathrm{C}$ for $4 \mathrm{~min}$, followed by 45 cycles consisting of $30 \mathrm{sec}$ at $94^{\circ} \mathrm{C}, 45 \mathrm{sec}$ at $52^{\circ} \mathrm{C}$ and $2 \mathrm{~min}$ at $72^{\circ} \mathrm{C}$ with final $5 \mathrm{~min}$ extension at $72^{\circ} \mathrm{C}$. After amplification, $12 \mu \mathrm{l}$ of the amplified product from each sample was resolved on agarose gel (1.4\% for RAPD and $2 \%$ ISSR) in $1 \mathrm{x}$ Tris acetate-EDTA (TAE) buffer (242 gTris, $57.1 \mathrm{ml}$ glacial acetic acid, $100 \mathrm{ml}$ EDTA, $\mathrm{pH}$ 8.0). Ethidium bromide $\left(0.5 \mu \mathrm{g} \mathrm{ml}^{-1}\right)$ was added in the buffer as inter calating agent. To estimate the size of amplified DNA fragments, $1 \mathrm{~kb}$ DNA ladder was used as marker. The gel was run at $120 \mathrm{~V}$ for $2 \mathrm{hr}$. After electrophoresis, the gel was viewed and stored in the Gel Documentation System.

\section{Resuls and Discussion}

The 15 RAPD primers produced a total of 154 markers (Table 2). The number of polymorphic markers and percentage of polymorphism was 125 and 81.2, respectively. The number of markers ranged from 4 to 16 . Four primers exhibited $100 \%$ polymorphism. 
Table.1 The details of the genetic stocks

\begin{tabular}{l|l|l}
\hline $\begin{array}{l}\text { Red } \\
\text { pericarp } \\
\text { rice }\end{array}$ & Landraces & Location/Source \\
\hline & $\begin{array}{l}\text { DesiDhan, Ram Jawain, AchhooBaldhar, Achhoo } \\
\text { Jattoo, Deval, Matali, BhrighuDhan }\end{array}$ & Chamba \\
\hline & Chohatoo & Kangra \\
\hline $\begin{array}{l}\text { IC3131159 } \\
\text { leaved } \\
\text { rice }\end{array}$ & $\begin{array}{l}\text { RLC-3, LalNakanda 41, TotuDhan, KalooDhan, Lalzhini, R-575, Purple } \\
\text { Baldhar,TaptaBaldhar, Kaladhan-1, Kaladhan-2, KrishanDhan, China Purple, HPLC- } \\
\text { 130, HPR-1194, HPR-2089, HPR-2178, Palampur Purple, Nagrota Purple }\end{array}$ & Shimla \\
\hline $\begin{array}{l}\text { Quality } \\
\text { rice }\end{array}$ & $\begin{array}{l}\text { IC3131183 } 31155 \\
\text { IC3131165, IC3131166 }\end{array}$ & Kandi \\
\hline & $\begin{array}{l}\text { LC99-1B, LC99-4B, LC99-5B, Local variety, RajpurBasmati, Ram Jawain-100, } \\
\text { Kalizhini, Chitizhini }\end{array}$ & Chamba \\
\hline Checks & $\begin{array}{l}\text { RP-2421, HPR-2143 } \\
\text { China-988 }\end{array}$ & Kullu \\
\hline
\end{tabular}

Table. 2 Primer codes, sequences, the number of scored band and number of polymorphic bands in RAPD and ISSR

\begin{tabular}{|c|c|c|c|}
\hline Primer code & Sequence $5, \ldots . . .3$ & Number of scored bands & Number of Polymorphic bands \\
\hline \multicolumn{4}{|l|}{ RAPD } \\
\hline OPF-05 & CCGAATTCCC & 10 & 9 \\
\hline OPF-09 & CCAAGCTTCC & 10 & 7 \\
\hline OPF-16 & GGAGTACTGG & 6 & 5 \\
\hline OPJ-13 & ССАСАCТАСС & 10 & 6 \\
\hline OPJ-20 & AAGCGGCCTC & 9 & 4 \\
\hline OPX-13 & ACGGGAGCCA & 9 & 8 \\
\hline OPX-20 & CCCAGCTAGA & 16 & 11 \\
\hline OPA-10 & GTGATCGCAG & 10 & 7 \\
\hline OPA-13 & CAGCACCCAC & 9 & 9 \\
\hline OPQ-05 & CCGCGTCTTG & 10 & 8 \\
\hline OPQ-06 & GAGCGCCTTG & 11 & 9 \\
\hline OPQ-10 & TGTGCCCGAA & 16 & 16 \\
\hline OPD-02 & GGACCCAACC & 11 & 11 \\
\hline OPD-05 & TGAGCGGACA & 8 & 6 \\
\hline OPU-15 & ACGGGCCAGT & 9 & 9 \\
\hline Total & & 154 & 125 \\
\hline \multicolumn{4}{|l|}{$\overline{\text { ISSR }}$} \\
\hline UBC8 10 & $(\mathrm{GA})_{8} \mathrm{~T}$ & 12 & 12 \\
\hline UBC8 14 & $(\mathrm{CT})_{8} \mathrm{~A}$ & 4 & 2 \\
\hline UBC8 & $(\mathrm{CT})_{8} \mathrm{G}$ & 7 & 7 \\
\hline UBC8 & $(\mathrm{GA})_{8} \mathrm{YT}$ & 10 & 10 \\
\hline UBC8 & $(\mathrm{GA})_{8} \mathrm{YC}$ & 2 & 1 \\
\hline UBC8 & $(\mathrm{CT})_{8} \mathrm{RA}$ & 3 & 1 \\
\hline UBC8 & $(\mathrm{CT})_{8} \mathrm{RG}$ & 4 & 3 \\
\hline UBC8 & $(\mathrm{GT})_{8} \mathrm{YC}$ & 4 & 3 \\
\hline UBC8 & $(\mathrm{TG})_{8} \mathrm{RT}$ & 4 & 3 \\
\hline UBC8 & $(\mathrm{TG})_{8} \mathrm{RC}$ & 6 & 6 \\
\hline UBC8 & $(\mathrm{GACA})_{4}$ & 3 & 3 \\
\hline Total & & 59 & 51 \\
\hline
\end{tabular}


Fig.1 RAPD marker profile of primer OPQ-5, $M=1 \mathrm{~kb}$ DNA ladder, 1-50: rice genotypes
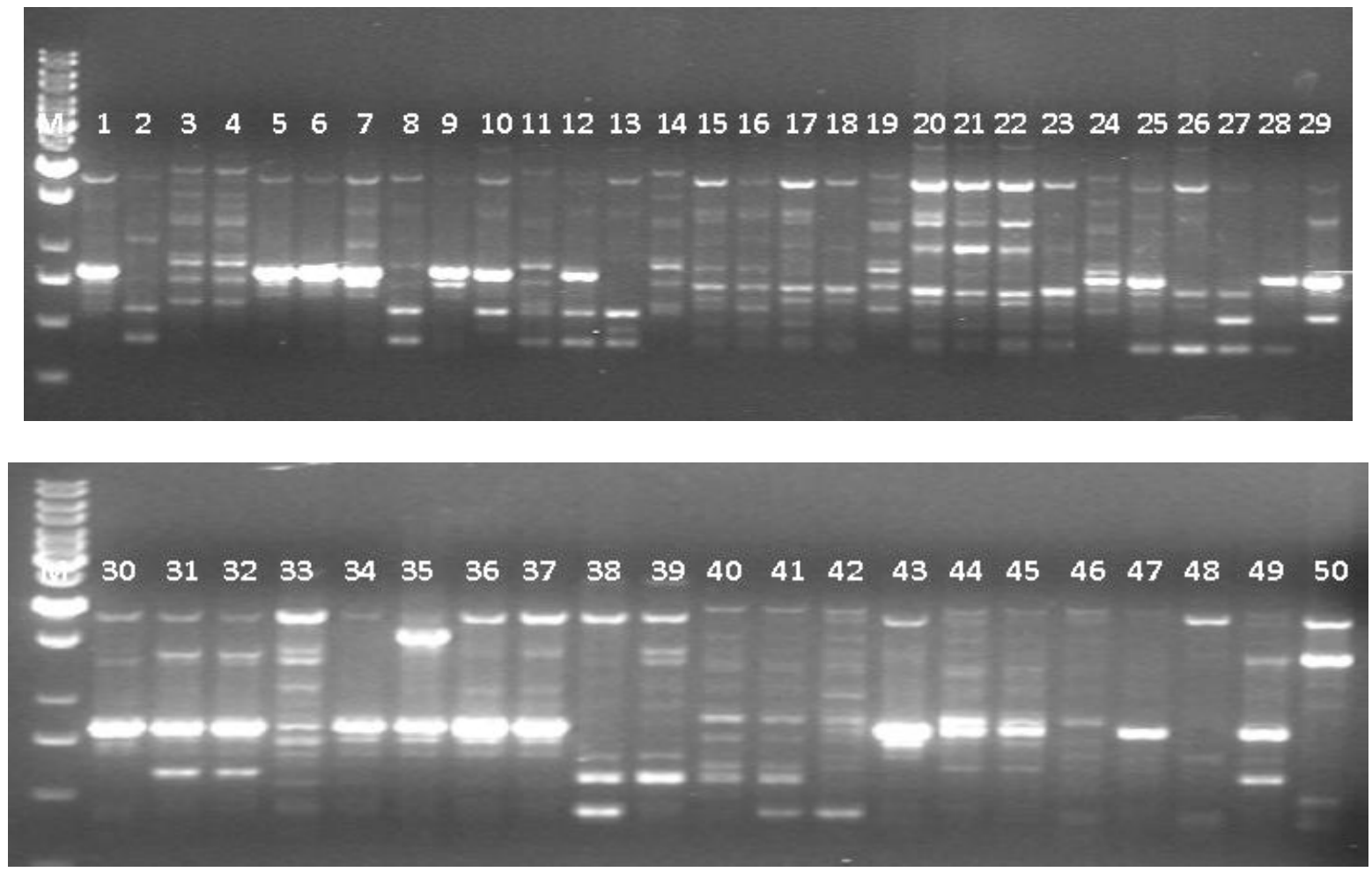

Fig.2 ISSR marker profiles of primer UBC8-68. M=1 kb DNA ladder, 1-50: rice genotypes

$M 123456789101112131415161718192021222324252627282930$

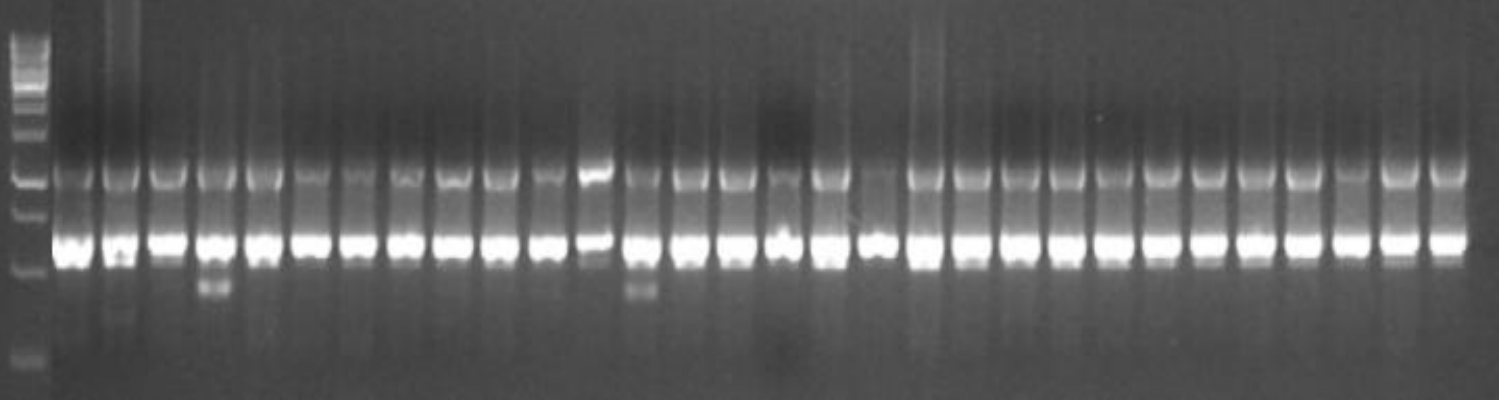

M $31 \quad 32 \quad 33 \quad 34 \quad 35 \quad 36 \quad 37 \quad 38 \quad 39 \quad 40 \quad 41 \quad 42 \quad 43 \quad 44 \quad 45 \quad 46 \quad 47 \quad 48 \quad 49 \quad 50$

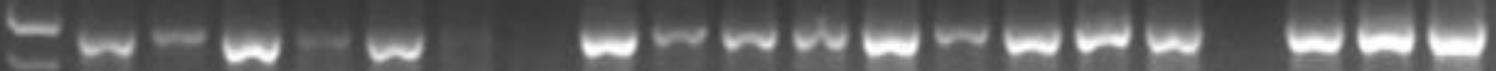

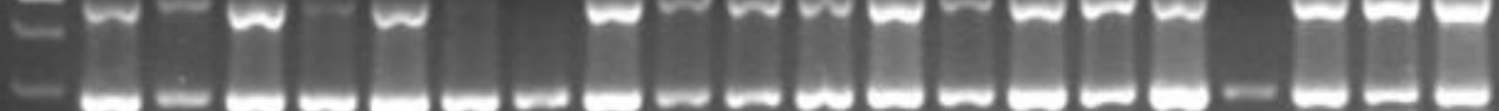
- - - 
Fig.3 (A) Dendrogram showing relationship among novelty rice landraces with RAPD and ISSR (data)

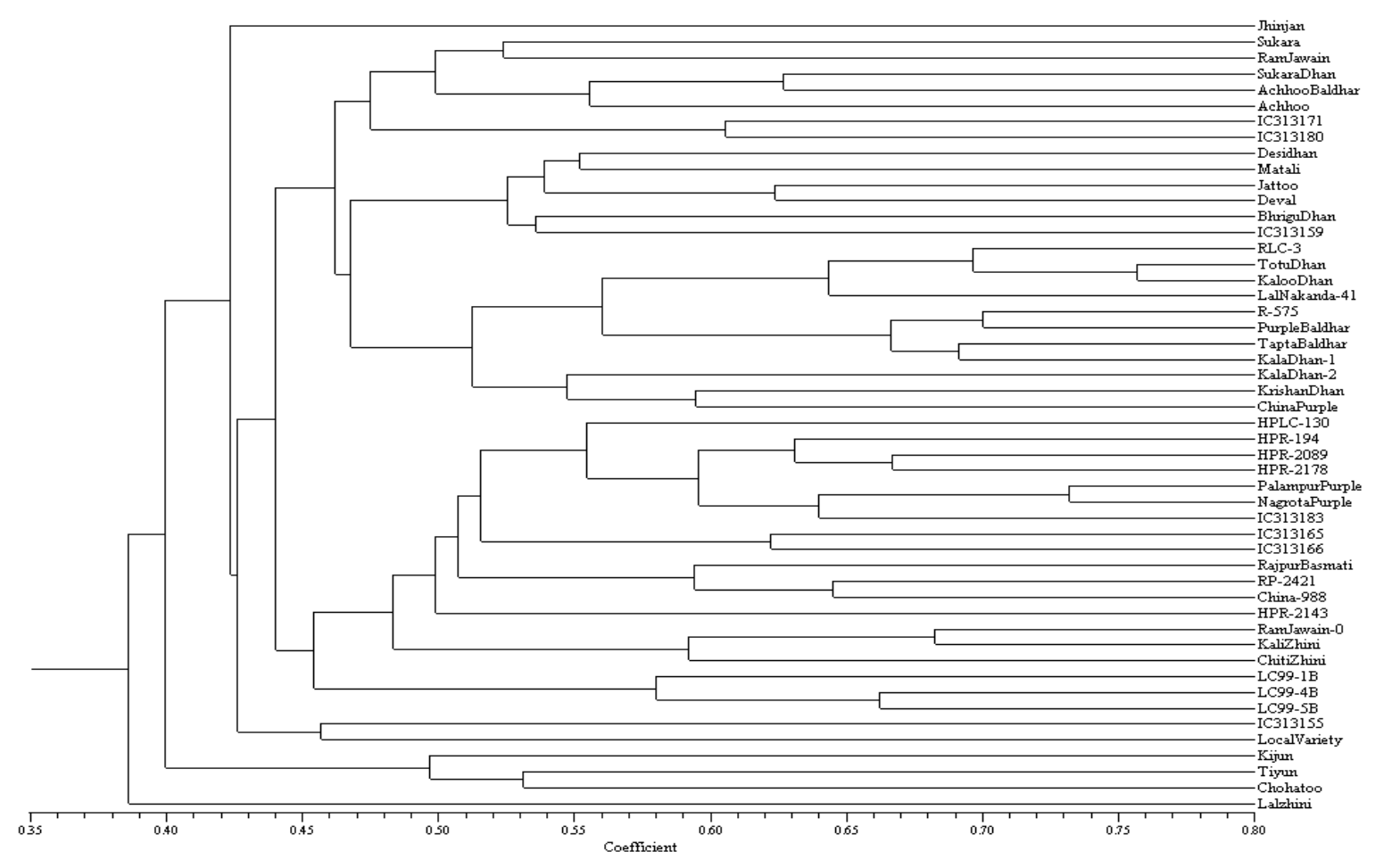

Fig.3 (B) Dendrogram generated using UPGMA analysis, showing relationship among 50 landraces of rice from Himachal Pradesh using RAPD and ISSR data (A) RAPD (B) ISSR

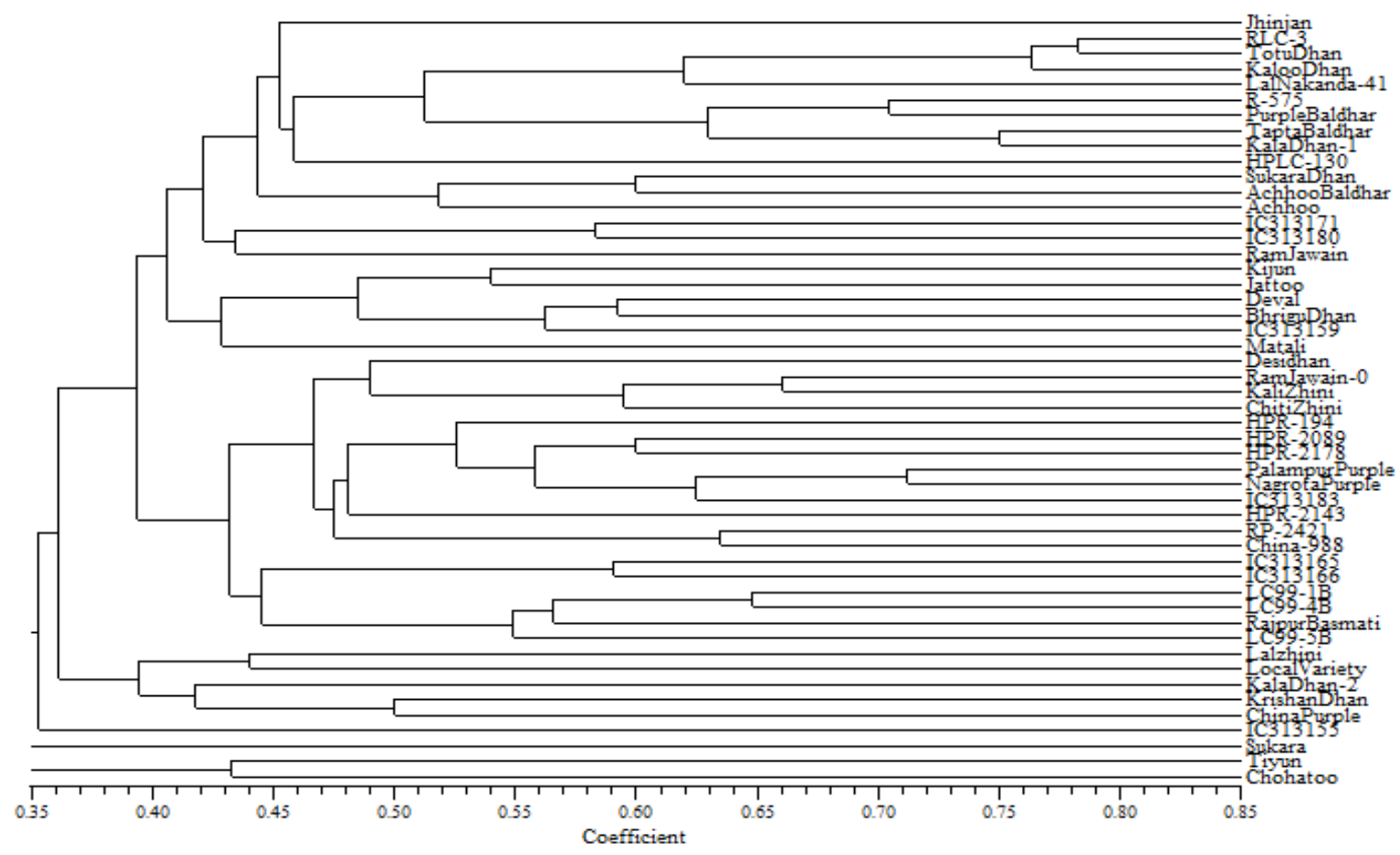


Out of these four, OPQ-10 generated maximum number of polymorphic markers. The highest polymorphism percentage by RAPD was shown by quality rice landraces (94.8\%), followed by red pericarp $(92.1 \%)$ and purple leaved rice landraces (86.7\%).

Based on RAPD markers, maximum similarity (0.78) was observed between 'RLC-3' and 'TotuDhan' and minimum similarity (0.20) was observed between 'Chohatoo' and 'IC3131165'. The dendrogram generated by the RAPD markers showed three clusters with a similarity coefficient of $30.5 \%$. The largest cluster I comprised of 41 genotypes and cluster II consisted of purple leaved rice and one quality rice i.e. Local Variety. Cluster III consisted of two genotypes of red rice (Tiyun and Chohatoo). Two genotypes (IC3131155 and Sukara) did not fall in the defined clusters. Cluster I had two sub-clusters $I_{a}$ and $I_{b}$ and sub-cluster $I_{a}$ had two further subgroups $I_{a-1}$ and $I_{a-2}$ and out of these two $I_{a-1}$ had all purple leaved rice, with similarity coefficient of $46 \%$. Besides one red pericarp rice, Jhinjan was also associated with this group at a similarity coefficient of $45.0 \%$. Sub-group $\mathrm{I}_{\mathrm{a}-2}$ had maximum genotypes of red pericarp rice landraces. $\mathrm{I}_{\mathrm{b}}$ had nine genotypes of quality rice, six genotypes of purple leaved rice, three checks and one genotype of red rice.

Eleven primers were selected to detect polymorphism based on their reliability (Table 2). These primers amplified a total of 59 ISSR markers among the 50 novelty rice landraces, of which $51 \quad(86.4 \%)$ were polymorphic with an average of 4.6 per primer (Fig. 2). The ISSR polymorphism percentage was higher than that of RAPD, in accordance with the Qian et al., 2000. The number of markers produced by different primers exhibited polymorphism. UBC8-10 generated maximum number of polymorphic markers while UBC8-41 and UBC8-43 generated least polymorphism. Red pericarp and quality rice showed the highest polymorphism $(86.7 \%)$, followed by purple leaved rice (Fig. 1). Maximum similarity (0.78) was observed between 'China Purple' and 'HPLC-130' and minimum similarity (0.30) between 'Kijun' and 'Chitizini'. The dendrogram generated by the ISSR markers showed 6 clusters with an overall similarity coefficient of $56.5 \%$. Cluster I (Jhinjan and Achhoo) and cluster II (Kijun and BhriguDhan) constituted of red pericarp landraces with similarity coefficient of $58.0 \%$. Cluster III was largest and further divided into two sub-clusters III $_{\mathrm{a}}$ and $\mathrm{III}_{\mathrm{b}}$ and $\mathrm{III}_{\mathrm{a}}$ included twelve genotypes of red pericarp ones, one purple leaved rice and two genotypes of quality rices (IC 3131155 and IC 3131166). Sub-cluster $\mathrm{III}_{\mathrm{b}}$ constituted of 16 of 19 of purple leaved rice and one genotype of quality rice landraces (IC 3131166) at similarity level of $59.5 \%$. Cluster IV had four genotypes of quality rice landraces and one genotype of red pericarped ones i.e. IC 3131159 at similarity coefficient of $58.0 \%$. Cluster $\mathrm{V}$ included all the three checks while Cluster VI constituted three genotypes of quality rice landraces (LC99-1B, LC99-4B and LC99-5B) at similarity level of $58.5 \%$. Checks of RAPD analysis were IC 3131183, Local variety and Lalzhini which were independent and did not fall in any cluster (Fig. 3B).

The rice landraces constitute a rich source of biodiversity and their conservation and utilization requires that their genetic structure is well characterized and understood. Higher level of polymorphism was detected by both RAPD and ISSR analysis as compared to Mathure et al., (2010). Jaccard's similarity coefficient ranged from 0.36 to 0.78 . The dendrogram obtained after pooling the data of two types of markers showed three clusters at similarity coefficient of $42.5 \%$. Cluster I is divided into two sub clusters $I_{a}$ and $I_{b}$. and out 
of these sub-cluster $I_{a}$ is further subdivided into three sub-groups $I_{a-1}, I_{a-2}$ and $I_{a-3}$ at similarity level of $46.8 \%$. Sub-group $\mathrm{I}_{\mathrm{a}-1}$ and $\mathrm{I}_{\mathrm{a}-2}$ included seven and six genotypes, respectively of red pericarp landraces with genetic similarity of $47.5 \%$ and $52.5 \%$ while subgroup $\mathrm{I}_{\mathrm{a}-3}$ contained eleven collections of purple leaved ones with similarity coefficient of $51.2 \%$. Sub-cluster $\mathrm{I}_{\mathrm{b}}$ consisted of seven collections of purple leaved landraces, nine genotypes of quality landraces and three checks. The three checks were grouped together with the similarity level of $50.0 \%$. Cluster II consisted of only two genotypes of quality rice while Cluster III comprised of three collections of red pericarp rice viz., Kijun, Tiyun and Chohatoo. The landraces Lalzhini and Jhinjan did not fall in any group (Fig. 3).

The high similarity between 'RLC-3' and 'Totu Dhan' was obtained in RAPD whereas, in ISSR it was maximum in 'China Purple' and 'HPLC-130'. On the other hand minimum similarity was between 'Chohatoo' and 'IC3131165', and 'Kijun' and 'Chitizini' for RAPD and ISSR, respectively. The lower similarity coefficient among genotype reflects their wider diversity and these cultivars can be crossed to widen the genetic base and exploit heterosis. The result of present study showed that both the markers worked effectively. RAPD showed the landraces 'IC3131155' and 'Sukara' as most divergent ones, while the land races 'Local Variety' and 'Lalzhini' are most diverse as per the ISSR result. This revealed the existence of sufficient amount of genetic variability among the landraces, which could be exploited further. The result of present study showed that both the markers worked effectively. Same results were reported by Lalhruaitluanga and Prasad 2009. Inconsistency between RAPD and ISSR analysis may be because reliability and reproducibility of RAPD in question $(\mathrm{Wu}$ et al., 2004) and it needs high level of standardization. The primers which proved very informative can be converted to sequence tagged sites (STS) and sequence characterized amplified regions (SCAR) for amplification of specific alleles which could be further utilized in rice genome analysis. The information gained from clustering behavior of landraces can be useful to design strategies for their management in gene banks.

\section{References}

Bhuyan, N., Borah, B.K. and Sarma, R.N. 2007. Genetic diversity analysis in traditional lowland rice (Oryza sativa L.) of Assam using RAPD and ISSR markers. Current Science 93: 967-972.

Lalhruaitluanga, H. and Prasad, M.N.V. 2009. Comparative results of RAPD and ISSR markers for genetic diversity assessment in Melocanna baccifera Roxb. growing in Mizoram State of India. African Journal of Biotechnology 8: 6053-6062.

Mathure, S., Jawali, N. and Nadaf, A. 2010. Diversity analysis in selected nonbasmati scented rice collection. Rice Science 17: 35-42.

Murray, M.G. and Thompson, W.F. 1980. Rapid isolation of high molecular weight plant DNA. Nucleic acids research 8: 4321-4326.

Qian, W., Ge, S. and Hong, D.Y. 2001. Genetic variation within and among populations of a wild rice Oryza granulata from China detected by RAPD and ISSR markers. Theoretical and Applied Genetics 102: 440-449.

Singh, D., Sirohi, A., Sharma, V.S., Kumar, V., Gaur, A., Dhaudhary, R. and Choudhary, N. 2006. RAPD based identification of farmers' collections of Kalanamak and traditional varieties of Basmati rice. Ind. J. Crop Science 1: 102-105. 
Virk, P.S., Zhu, J., Newbury, H.J., Bryan, G.J., Jackson, M.T. and Ford-Lloyd, B.V 2000. Effectiveness of different classes of molecular marker for classifying and revealing variation in rice (Oryza sativa) germplasm. Euphytica 112: 275-284.
Wu, C.J., Cheng, Z.Q., Huang, X.Q., Yin, S.H., Cao, K.M. and Sun, C.R. 2004. Genetic diversity among and within populations of Oryza granulata from Yunnan of China revealed by RAPD and ISSR markers: implications for conservation of the endangered species. Plant Science 167: 35-42.

\section{How to cite this article:}

Ritu Sood, Sanchit Thakur, Neelam Bhardwaj and Kaushik, R.P. 2018. Genetic Diversity Analysis of Rice Landraces of NW Himalayas Using RAPD and ISSR Markers. Int.J.Curr.Microbiol.App.Sci. 7(04): 548-555. doi: https://doi.org/10.20546/ijcmas.2018.704.064 